\title{
Pulverised-Coal Combustion with Staged Air Introduction: CFD Analysis with Different Thermal Radiation Methods
}

\author{
Risto V. Filkoski* \\ University "Sts Cyril and Methodius”, Faculty of Mechanical Engineering Karpoš II, P.O.Box 464, Skopje, Republic of \\ Macedonia
}

\begin{abstract}
Combustion chamber designers endeavour to achieve optimum operating conditions that give maximum combustion efficiency, together with minimum pollutant formation rate. Modelling of fossil fuel utility boilers has reached a remarkable development in recent years. Particularly, the application of computational fluid dynamics (CFD) modelling technology and other advanced mathematical methods offer opportunities for analysis, optimisation and options examination in order to increase the overall efficiency of the energy facilities. The main purpose of the present study was to investigate how the results obtained with two radiative heat transfer methods, the P1 approximation method and the discrete ordinates (DO) method, fit temperature field in a boiler furnace on pulverised coal, with implemented over-fire air (OFA) ports. The overall framework of the CFD modelling approach is described. The numerical modelling results for boiler baseline operating conditions are compared with a test matrix of local temperature measurements. An accuracy analysis of the P1 and DO methods is done on a basis of a comparison between the numerically obtained and measured temperature profiles.
\end{abstract}

Keywords: Coal combustion, heat transfer, thermal radiation, CFD techique, modelling.

\section{INTRODUCTION}

Well-grounded technical solutions of boiler furnaces and combustion chambers are aimed to achieve operating conditions that give optimal heat transfer, maximum combustion efficiency and minimum pollutant formation rate. This leads to increasing the overall efficiency of the energy facilities and is particularly important in the cases when coal is used as fuel. Despite the calls for larger utilisation of gas and renewable energy sources, the role of coal is crucial and, probably, its importance as energy resource is not going to be endangered significantly in the coming decade or two. There is a certain re-emergence of coal as a primary fuel for power generation, as a result of technological changes that have reduced the amount of pollutants and particulate emissions to the atmosphere, and recent international worries about security of gas supply. At the same time, the interest on performance optimisa-tion of utility boilers has become very relevant, aiming at extending their lifetime, increasing the overall efficiency and reducing the emissions of pollutants, which is quite clear with the rising costs and increasing demand for energy.

In many combustion devices, including boiler furnaces, the radiant heat transfer is the dominant mode of energy transfer. In order to predict accurately the temperature field, which is in direct correlation with the combustion efficiency and $\mathrm{NO}_{\mathrm{x}}$ formation, it is important to utilise proper radiative heat transfer model. As a part of the efforts to establish

*Address correspondence to this author at the University "Sts Cyril and Methodius", Faculty of Mechanical Engineering Karpoš II, P.O.Box 464, Skopje, Republic of Macedonia; Tel: +389 23099 224; Fax: +389 23099 298; E-mail: rvfilko@mf.edu.mk; rvfilko@yahoo.com appropriate modelling and simulation approach for certain conditions, the main objective of the present study was to investigate how some established thermal radiation methods describe the temperature field in a furnace of utility boiler on pulverised coal with staged air/fuel introduction.

\section{MODELLING AND SIMULATION TECHNIQUES FOR FURNACE APPLICATIONS}

The mathematical modelling and numerical simulation have already been widely accepted as low-cost, efficient engineering tools for analysis and optimisation of combustion systems [1]. These tools considerably facilitate the investigation of the influence of various process and design parameters, such as fuel proximate and ultimate analysis, particle size distribution, air and fuel inlet distribution, overall furnace geometry (furnace shape, air and fuel inlets, layout of air staging nozzles, recirculation holes), burners' design, flame-wall interaction phenomena, heat transfer degradation, slagging propensity etc. to the heat transfer conditions, overall combustion efficiency, plant efficiency and the emission of pollutants. Advanced combustion models and computational fluid dynamics (CFD) techniques are extensively used to accurately solve the aerodynamics equations involved in the problem, and to predict coal burnout and heat transfer in large utility boilers. Compared to a purely experimental study, CFD modelling approach offers significant benefits: cost and time reduction, reproducibility of boundary conditions, as well as detailed insight into the complex interacting physical phenomena determining the combustion process.

A comprehensive historical review of the modelling approaches and techniques of pulverised coal boilers is given in [2], pointing out very different standpoints and objectives. 
The traditional approach of boiler manufacturers, that is essentially identical to the usual design practices of boilers and furnaces of very different nature, is based on the use of relatively simple semi-empirical models, developed in pilot plants or inferred from the practical experience.

Since the early 70 s, more elaborated models for predicting heat transfer in furnaces started to appear. A typical engineering calculation method is elaborated in [3]. In the same work, a plug-flow method is described, aimed for simple furnace calculations, and known as zone method. The method is based on division of the domain into a few amount of volume cells and it has been widely used by researchers and engineers (for instance [4, 5]). This was some kind of a predecessor of the application of the popular Hottel zone method for radiative heat transfer, already available in literature [6], but still not applied in the design of utility boilers, since it requires previously defined reliable velocity field and heat release (combustion) patterns. The former Soviet approach to the furnace modelling is also expressed through the works of several other authors $[7,8]$.

The adoption of the various forms of zone methods coincided and, in some extent, was one of the preconditions for development of CFD techniques, with all their advantages and shortcomings. Nowadays researchers' efforts are concentrated in two general directions: (1) to improve the fundamental models of the complex phenomena that occur in the combustion systems and (2) to adopt some simplifications in order to make possible the extrapolation of research results to industrial applications.

The permanent progress in computers capability over the last two decades has enabled development and application of massive mathematical models of turbulent flows, heat transfer and combustion in the furnaces and extensive use of CFD techniques, with quite satisfactory results [9-14]. Threedimensional comprehensive models of industrial-scale furnaces have been developed and successfully applied for years now [9-20, 22]. There are also combinations of original models of separate processes and existing computational codes [23, 24]. Of course, there is still an area for further improvements, having as a subject a detailed mathematical description of physical and chemical processes in certain specific conditions. Numerical codes describing the processes in coal-fired boilers, based on solution of differential conservation equations, have been a subject of many investigations $[10,15-20,22]$. While some consider numerical aspects [17] or aerodynamics [22] in small-scale furnace isothermal models, others present comprehensive combustion models of large-scale furnaces. The majority of the models use variations of the SIMPLE algorithm for coupling the continuity and momentum equations. Despite some weaknesses, the $k$ - $\varepsilon$ turbulen-ce model, or some derivatives, like RNG $k$ - $\varepsilon$ model [10], or $k-\varepsilon-k_{p}$ two-phase turbulence model [19], are often used in combustion systems. Gas phase conser-vation equations are mostly time-averaged, but some prefer the Favre-averaged equations instead [16].

Two-phase flow is usually described by EulerianLagrangian approach and PSI-Cell method for taking into account the influences between phases, with some exceptions using Eulerian-Eulerian approach, or two-fluid trajectory model [19].
Most of the combustion sub-models given in $[10,15,16$, $18-20,22]$ separately treat particle devolatilisation, char oxida tion and additional gas phase reactions. One of the most important segments of the furnace modelling is the way of radiative heat transfer incorporation. Thermal radiation in the furnaces can be modelled by means of various approaches, like discrete transfer method [15], discrete ordinates method [16, 19-21], six-fluxes method [18], Monte Carlo method [10], or so called P-N approximation method [25], including its P-1 variant, as it is used in [26, 27]. In general, it should be pointed out that a comprehensive model of the furnace processes must balance sub-models sophistication with computational practicality.

\section{DESCRIPTION OF THE CASE STUDY: BOILER AND FUEL MAIN PROPERTIES AND FURNACE GEOMETRY}

The modelling technique described in this paper has been validated against data acquired from the corner-fired pulverised coal boiler at a power plant with gross output of 160 MWe [28]. A top view (cross-section), showing the boiler dimensions and inlet air trajectories, is presented in Fig. (1) [28]. The boiler furnace is rectangular in shape, $11.58 \mathrm{~m}$ long and $8.53 \mathrm{~m}$ wide. The inlet air and coal are fed from the furnace corners, at $42^{\circ}$ and $31^{\circ}$, as shown, to create a fireball swirling (counterclockwise, as viewed from the top). The boiler is retrofitted with low- $\mathrm{NO}_{\mathrm{x}}$ burners, concentric firing system (CFS) ports, close-coupled overfire air (CCOFA) and separate overfire air (SOFA) ports. The boiler was modified with fifteen $152 \mathrm{~mm}$ diameter circular ports at various levels, which can accommodate appropriate water-cooled probes for temperature measurement. The port locations are selected taking into account the importance of data from various locations. A schematic diagram of the boiler furnace represented in Fig. (1), also indicates the location of various fuel, air and measurement ports.

The coal properties for the test case and the boiler main operating conditions are listed in Tables $\mathbf{1}$ and $\mathbf{2}$ [28]. The secondary air flow includes air through CFS, CCOFA and SOFA ports. A schematic representation of the ports: top SOFA, mid SOFA, bottom SOFA, top CCOFA, bottom CCOFA, coal burners No. 1-4, CFS ports and auxiliary oil ports, is given in Fig. (1) [28].

Some details of the burners' configuration, including the height of each port with respect to the datum, which is at the bottom of the ash hopper, and the port area, are shown in Table 3 [28]. For the modelling purposes, it was assumed that the air was evenly distributed between all inlet ports in proportion to the areas reported in Table $\mathbf{3}$ and that those areas were adjusted for the test according to the percentage opening. The inlet air was heated to $260^{\circ} \mathrm{C}$ and the ratio of primary air to as-received coal mass flow rate was 1.7.

The simulations have been performed on a basis of the Fluent CFD code, version 6.1, adapted for pulverised coal industrial and utility scale boiler furnaces. Geometry outline of the calculation domain and the numerical mesh are presented in Fig. (2). Special attention has been paid to the grid design, in order to reduce numerical error as much as possible. The fact that the smallest lengths in combusting turbulent fluid flows are in the much smaller magnitude order, compared to the huge dimensions of utility boiler furnaces, 


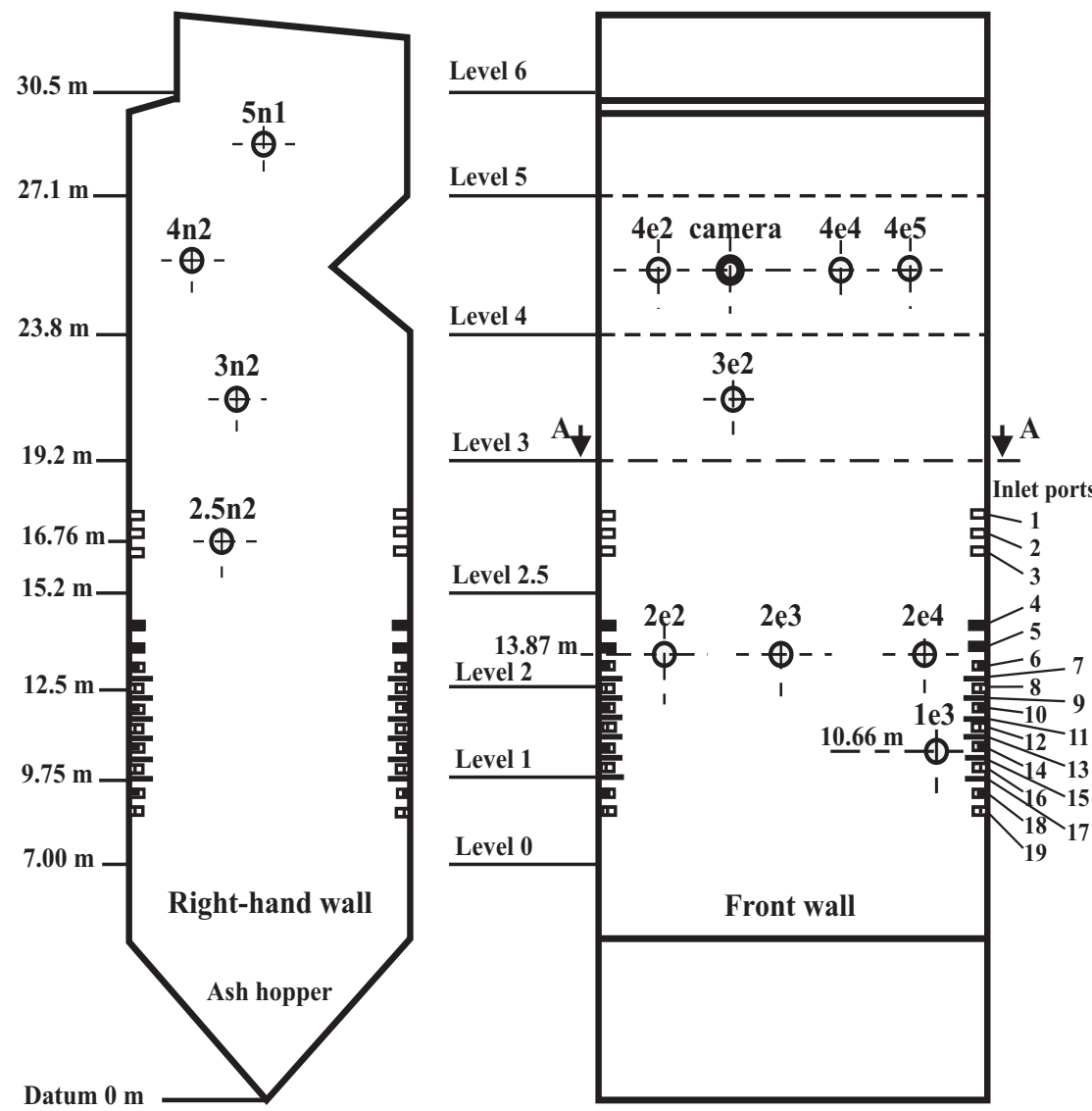

\section{Section A-A}

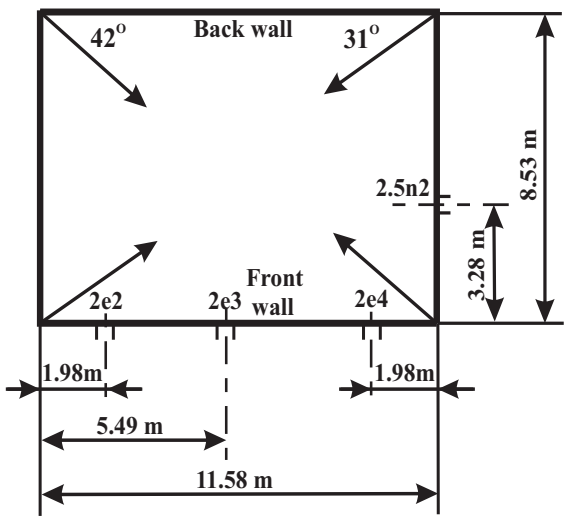

O $152 \mathrm{~mm}$ ports

Coal inlets $(6,10,14,18)$

m Aux. oil $(8,12,16,19)$

ㅁ SOFA $(1,2,3)$

- CCOFA $(4,5)$

- CFS air $\quad(7,9,11,13,15,17)$

Fig. (1). Schematic representation of the boiler furnace with disposition of air and fuel inlets, measurement ports and direction of burners [28].

make it necessary either to discretise the solution domain using control volumes with dimensions of the order of some milimeters in all directions, either to find some other solution. Considering the time available and the computer resources, the first option is not feasible.

Table 1. Coal Properties (as Received) [28]

\begin{tabular}{|c|c|}
\hline Proximate Analysis & Value \\
\hline \hline Total moisture, wt \% & 4.1 \\
\hline Volatile matter, wt $\%$ & 28.3 \\
\hline Fixed carbon, wt $\%$ & 55.7 \\
\hline Ash, wt $\%$ & 12.0 \\
\hline Mean particle diameter, $\mu \mathrm{m}$ & 27 \\
\hline Coal heating value, $\mathrm{kJ} / \mathrm{kg}$ & 31040 \\
\hline
\end{tabular}

As a compromise, much denser mesh is utilised in regions where large gradients of variables can be expected, such as the near-burner-regions. In this case, there are totally 688,886 tetrahedral hybrid cell elements in the domain. According to the previous experiences with simulations of other boiler furnaces with comparable domain dimensions and complexity, the grid is fine enough to give gridindependent solutions, showing satisfactory convergence and accuracy and, at the same time, to meet the restrictions in computational time [26, 27, 29].

Table 2. Boiler Operating Conditions [28]

\begin{tabular}{|c|c|}
\hline Parameter, Unit & Value \\
\hline \hline Gross load, MWe & 156 \\
\hline Coal feed, $\mathrm{kg} / \mathrm{h}$ & 50,200 \\
\hline Primary air flow rate, $\mathrm{kg} / \mathrm{h}$ & 85,340 \\
\hline Air temperature, ${ }^{\circ} \mathrm{C}$ & 260 \\
\hline Secondary air, $\mathrm{kg} / \mathrm{h}$ & 546,000 \\
\hline Burner tilt, deg. & -5 \\
\hline
\end{tabular}

Thermocouple pyrometry, as a practical and reliable method of measuring gas temperature in full-scale boilers, is used in this case. The procedure for temperature measurements is described in details in [28]. Gas temperature measurements are obtained with a type $\mathrm{S}, \mathrm{Pt} / \mathrm{Pt}-10 \% \mathrm{Rh}$ 
Table 3. Geometry Properties of the Furnace Inlet Ports

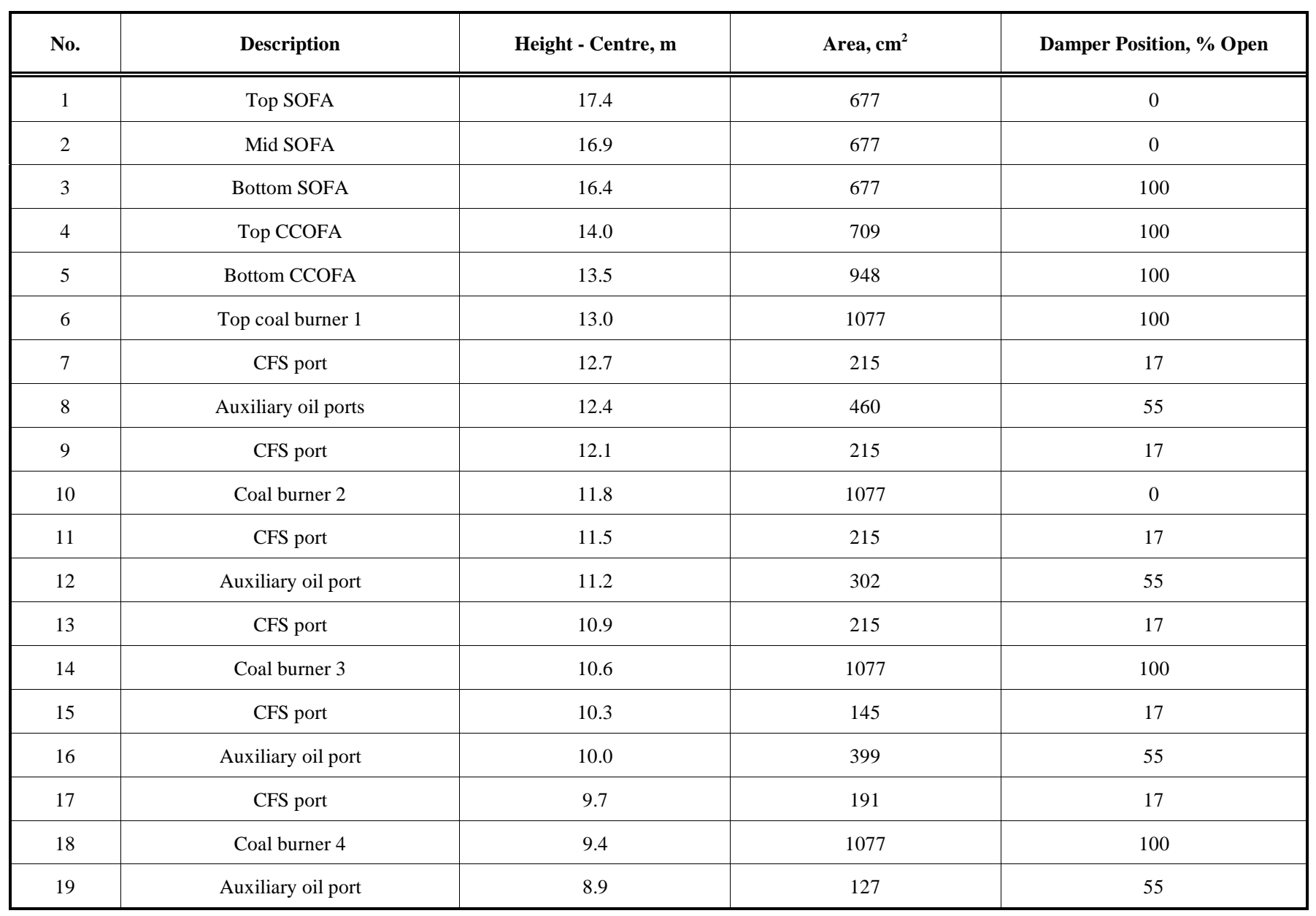

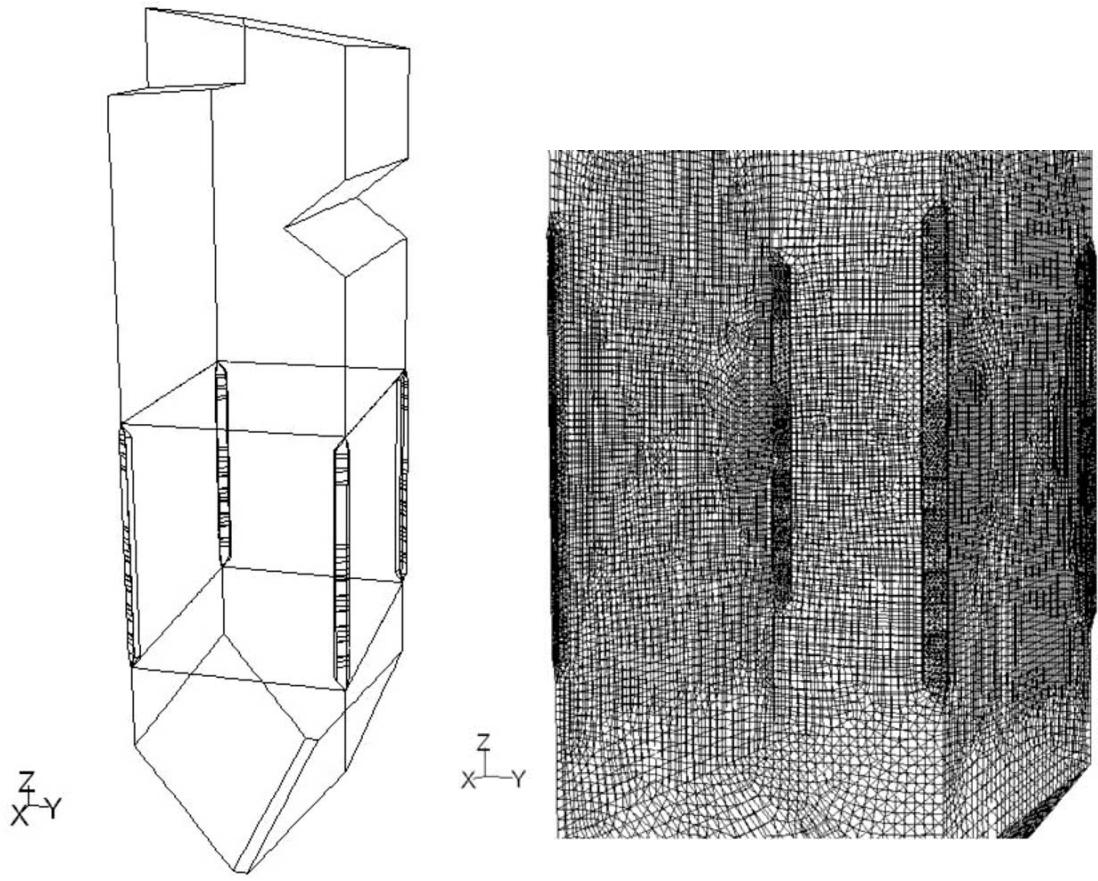

Fig. (2). Furnace geometry and the numerical mesh in the burners' region. 
thermocouple in a triply shielded suction pyrometer. A venturi pump is used to draw combustion products through an opening in the outer ceramic tube and between the smallest and medium-sized tubes.

\section{MATHEMATICAL MODELLING APPROACH}

Aerodynamic processes in the boiler furnaces are complex and very important for overall proper operation of the energy facilities. A furnace of a steam boiler with pulverised coal combustion, as an object for numerical modelling, is characterised with a compressible particle-laden flow, reactions and heat transfer phenomena occurring in the turbulent flow. The most important physical and chemical processes, which have to be covered by the model, are the turbulent two-phase flow of gas and suspended particles, the release of the coal volatile matter, the chemical reactions of the released species, the burnout of the char particles and the heat transfer governed by thermal radiation. Accordingly, the comprehensive boiler furnace model consists of three main interacting parts: the flow model for the turbulent two-phase flow, the reaction model for the homogenous and heterogeneous combustion reactions, and the heat transfer model with emphasize on the thermal radiation as the most important mechanism.

One of the possibilities for improvement of the operation efficiency of the pulverised coal-fired boilers is wellgrounded technical solution aimed at reduction of $\mathrm{NO}_{\mathrm{x}}$ emission, together with the subsequent suppressing of heat loss due to inefficient combustion. The present research was concentrated on an analysis of the flow field, temperature field and combustion efficiency, as a result of a staged air introduction, but in this work only the temperature field is a subject of analysis.

Although the smallest lengths in combusting turbulent fluid flows are in the magnitude order that is much smaller than the boiler furnaces dimensions, in most cases, the timeaveraged mean value of the flow situation is of primary interest. Proper turbulence models are used as a remedy for this problem. For the sake of computational performance, the simple $k-\varepsilon$ turbulence model is applied in majority of applications, although some predictive quality is sacrificed. Due to the assumptions of prevailing isotropic turbulence, this relatively crude model exhibits some weaknesses when applied to flows with strong streamline curvature, as in the near-burner area of swirl burners. Also, very often, in boiler furnaces significant recirculation regions appear, especially near the furnace corners. The $k$ - $\varepsilon$ model is known to exhibit certain predicaments in accurately describing such phenomena. Therefore, the standard $k$ - $\omega$ turbulence model is employed in this case as a reasonable compromise [30]. As the $k$ - $\omega$ model has been modified over the years, production terms have been added to both the $k$ and $\omega$ equations, which have improved the accuracy of the model predictions. Common values of the constants are used in the transport equations: $\alpha_{\infty}{ }^{*}=1, \alpha_{\infty}=0.52, \alpha_{0}=1 / 9, \beta_{\infty}{ }^{*}=0.09, \beta_{i}=0.072, R_{\beta}=8$, $R_{k}=6, R_{\omega}=2.95, \zeta^{*}=1.5, M_{t 0}=0.25, \sigma_{k}=2.0$ and $\sigma_{\omega}=2.0$. Coupling of velocity and pressure is achieved by the SIMPLEC algorithm.

A simulation of pulverised coal combustion involves modelling of a continuous gas phase flow and its interaction with a discrete phase. The particles, traveling through the gas, devolatilise and undergo char combustion, creating sources of fuel for reaction in the gas phase. In this work, the concentration of species and the chemical reactions are modelled using the mixture fraction/probability density function (PDF) approach and the full equilibrium chemistry, where the turbulence-chemistry interaction is modelled using a double-delta PDF [31]. It is assumed that the two-streams PDF mixture consists of 20 volumetric species. The equilibrium chemistry model assumes that the chemistry is rapid, so that chemical equilibrium always exists at the molecular level. An algorithm based on the minimization of Gibbs free energy [31] is used to compute species mole fractions. The equilibrium model is useful, since it can predict the formation of intermediate species and it does not require knowledge of detailed chemical kinetic rate data. Instead of defining a specific multi-step reaction mechanism, it needs simply to define the important chemical species that will be present in the system. The mole fraction of each species is then predicted, based on chemical equilibrium assumption.

Regarding the influence of the membrane walls to the aerodynamics, it is assumed that the particle-to-wall collisions occur with certain elasticity. This is defined by setting reflecting boundary condition type, with constant discrete phase reflection coefficients - normal and tangent.

The polydisperse coal particle size distribution is relatively narrow and it is assumed to fit the Rosin-Rammler equation. Particle trajectory data, size distribution parameters, coal devolatilisation and coal combustion parameters used in the model are given in Tables $\mathbf{4}$ and $\mathbf{5}$.

Table 4. Coal Particle Trajectory Data

\begin{tabular}{|l|c|}
\hline Parameter & Value \\
\hline \hline Number of particle stream start locations & 16 \\
\hline Maximum number of steps in each trajectory & 1200 \\
\hline Length scale & $0.1 \mathrm{~m}$ \\
\hline Particles distribution - Rosin-Rammler & \\
\hline Number of particle diameters & 6 \\
\hline Mean diameter & $0.027 \mathrm{~mm}$ \\
\hline Minimum diameter & $0.01 \mathrm{~mm}$ \\
\hline Maximum diameter & $0.15 \mathrm{~mm}$ \\
\hline Spread parameter & 2.0 \\
\hline
\end{tabular}

\section{HEAT TRANSFER AND THERMAL RADIATION MODELLING}

In this case, the energy equation is used in the following total enthalpy form

$$
\frac{\partial}{\partial t}(\rho H)+\nabla \cdot(\rho \vec{v} H)=\nabla \cdot\left(\frac{k_{t}}{c_{p}} \nabla H\right)+S_{h}
$$

where $\rho$ denotes gas-phase density, $k_{t}$ is the turbulent thermal conductivity, defined according to the turbulence 
model being used. The term $S_{h}$ includes the heat of chemical reactions and any other volumetric heat sources.

Under the assumption that the Lewis number (Le) is equal to 1 , the conduction and species diffusion terms combine to give the first term on the right-hand side of the above equation, while the contribution from viscous dissipation appears in the non-conservative form as the second term.

Table 5. Coal Combustion Parameters

\begin{tabular}{|l|}
\hline \multicolumn{2}{|l|}{ a) Coal devolatilisation data } \\
\hline Devolatilisation model - two competing rates \\
\hline 1) First rate \\
\hline - pre-exponential factor \\
\hline - activation energy \\
\hline - weighting factor \\
\hline 2) Second rate \\
\hline - pre-exponential factor \\
\hline - activation energy \\
\hline - weighting factor \\
\hline b) Combusting particles properties \\
\hline Density \\
\hline Specific heat capacity - polynomial profile \\
\hline Thermal conductivity \\
\hline Mass diffusion limited rate constant $4.5 \cdot 10^{-1}$ \\
\hline Kinetic rate pre-exponential factor 0.002 \\
\hline Activation energy \\
\hline
\end{tabular}

The total enthalpy $\mathrm{H}$ is defined as:

$\mathrm{H}=\sum_{j} Y_{j} H_{j}$

where $Y_{j}$ is the mass fraction of species $j$ and $H_{j}$ is sensible enthalpy of species $j$ :

$\mathrm{H}_{\mathrm{j}}=\int_{T_{r e f, j}}^{T} c_{p, j} d T+h_{j}^{0}\left(T_{r e f, j}\right)$

In this equation, $c_{p, j}$ is specific heat capacity and $h_{j}^{0}\left(T_{r e f, j}\right)$ is a formation enthalpy of species $j$ at the reference temperature $T_{r e f, j}$.

Energy sources due to radiation, as well as the heat transfer between the continuous and the discrete phase, are included through the term $S_{h}$ in Eq. (1).

The furnace of a pulverised coal-fired boiler is an example of a space with an emitting-absorbing and scattering medium. The balance of energy passing in a specified direction $\Omega$ through a small differential volume in an emittingabsorbing and scattering medium, at position $\mathbf{r}$ in direction $\mathbf{s}$, including the effect of the presence of discrete phase, can be represented through this form of the radiative transfer equation (RTE)

$$
\begin{aligned}
& \frac{d I(\mathbf{r}, \mathbf{s})}{d s}+\left(a+a_{p}+s_{p}\right) I(\mathbf{r}, \mathbf{s})= \\
& \alpha n^{2} \frac{\sigma T^{4}}{\pi}+E_{p}+\frac{\sigma_{p}}{4 \pi} \int_{0}^{4 \pi} I\left(\mathbf{r}, \mathbf{s}^{\prime}\right) \Phi\left(\mathbf{s} \cdot \mathbf{s}^{\prime}\right) d \Omega^{\prime}
\end{aligned}
$$

where $I(\mathbf{r}, \mathbf{s})\left[\mathrm{W} / \mathrm{m}^{2}\right.$ srad] is the radiation intensity, which is a function of the wave length, position and direction; $\mathbf{r}$ is a position vector; $\mathbf{s}$ is a direction vector; $a$ denotes absorption coefficient, $a_{p}$ is the equivalent absorption coefficient due to the presence of particles; $\sigma_{p}$ is the equivalent particle scattering factor and $E_{p}$ is the equivalent emission of the particles, explained bellow. Also, in Eq. (4) $\Phi$ is phase function, which represents the probability that a wave of frequency $v$ from direction $\mathbf{s}$ in elementary space angle $d \omega^{\prime}$ will switch (deviate) towards direction $\mathbf{s}$ ' inside the angle $d \omega$ with frequency $v ; \mathbf{s}^{\prime}$ is a vector of scattering direction.

The particles equivalent emission coefficient $\left(E_{p}\right)$ and the equivalent absorption coefficient $\left(a_{p}\right)$ are given with the following expressions

$E_{p}=\lim _{V \rightarrow 0} \sum_{n=1}^{N} \varepsilon_{p n} A_{p n} \frac{\sigma T_{p n}^{4}}{\pi V}$

and

$a_{p}=\lim _{V \rightarrow 0} \sum_{n=1}^{N} \varepsilon_{p n} \frac{A_{p n}}{V}$

In Equations (5) and (6), $\varepsilon_{p n}, A_{p n}$, and $T_{p n}$ are emissivity, projected area, and temperature of particle $n$. The summation is over $N$ particles in volume $V$.

\section{SELECTION OF A RADIATION MODEL}

The selection of the most appropriate thermal radiation model in certain conditions depends on various factors, such as the optical thickness, the possibility for inclusion the scattering and emissivity effects, the way the model is treating the effects of the presence of discrete phase and the model behaviour in the case of medium with localised heat sources. In this case, the Discrete Ordinates (DO) and the P-1 models are utilised [21, 25, 32-35], since they effectively comprise the influence of the discrete phase presence in the boiler furnace, unlike some other frequently used models in thermal engineering applications, like the Discrete Transfer Radiation Model (DTRM) [15, 32, 36].

The optical thickness of the radiating medium $a L$, where $L$ is characteristic path length, is one of the indicators of which model to use in the analysed problem. If the optical thickness is large, $a L>>1$ or $a L>1$, the P-1 model should typically be used. The DTRM and the DO model work across the range of optical thicknesses, but are substantially more expensive to use.

The P-1 and DO models account for scattering and emissivity, while the DTRM neglects it. Also, only the P-1 and DO models account for exchange of thermal radiation between the gas and particulates. 
In problems with localised heat sources, such as solid fuel particles, the DO model is probably the best suited for computing radiation.

The DO model considers the radiative transfer equation in the direction $\mathbf{s}$ as a field function and, including the contribution of a discrete phase of particulates on radiation, the RTE can be written as Eq. (4). In this case, the so-called S6 approximation was applied in the framework of the DO model, corresponding to 48 flux approximations [21]. This approach yields sufficiently reasonable results for the amount of the numerical work. The higher-order approximations, such as the $\mathbf{S} 8$, with 80 flux approximations, require considerably more numerical effort.

The the P-1 model, as simplified P-N differential approximation, has certain specific advantages over other models in treating the radiative energy transfer in a grey absorbing and emitting medium with presence of particulates. It is relatively simple, treats the RTE as an easy-to-solve diffusion equation and it can be easily applied to complicated geometries. For a gray, absorbing, emitting, and scattering medium containing absorbing, emitting, and scattering particles, the transport equation for the incident radiation can be written as

$\nabla \cdot(\Gamma \nabla G)+4 \pi\left(a \frac{\sigma T^{4}}{\pi}+E_{p}\right)-\left(a+a_{p}\right) G=0$

where $E_{p}$ is the equivalent emission and $a_{p}$ is the equivalent absorption coefficient of the particles.

The utilised values of the particles thermal radiation characteristics are derived as approximations of data from various sources $[37,38]$. The scattering coefficient, along with the absorption coefficient, describes the change in radiation intensity per unit length along the path through the furnace medium. In order to include the effect of an anisotropic scattering, in this case, a Delta-Eddington phase function is implemented in the following form:

$\Phi\left(\mathbf{s}^{\prime} \mathbf{s}^{\prime}\right)=2 f \delta\left(\mathbf{s} \cdot \mathbf{s}^{\prime}\right)+(1-f)\left(1+C \mathbf{s} \cdot \mathbf{s}^{\prime}\right)$

The variable absorption coefficient, in this case, is defined as composition-dependent, with a local value of $a$ as a function of the local mass fractions of water vapour $\left(\mathrm{H}_{2} \mathrm{O}\right)$ and $\mathrm{CO}_{2}$. For that purpose, the weighted-sum-of-gray-gases model (WSGGM) is used [39], which is a compromise between the over-simplified gray gas model and a complete model that takes into account particular absorption bands. According to the WSGGM, the total emissivity over the distance $\mathrm{s}$ is presented as

$\varepsilon=\sum_{i=0}^{I} a_{\varepsilon, i}(T)\left(1-e^{-\kappa_{i} p s}\right)$

where $a_{\varepsilon, i}$ are the emissivity weighting factors for the $i$-th "fictitious" gray gas, the bracketed quantity is the $i$-th gray gas emissivity, $\kappa_{i}$ is the absorption coefficient of the $i$-th gray gas, $p$ is the sum of partial pressures of all absorbing gases, and $s$ is the path length. In the above equation, the path length $s$ is calculated according to the mean-beamlength approach, based on an average dimension of the domain. The effect of the soot concentration on the radiation absorption coefficient is included in the simulations. The absorption coefficient of a mixture of an absorbing (radiating) gas and soot is calculated as a sum of the absorption coefficients of pure gas and pure soot [40]:

$a=a_{g}+a_{s}$

where $a_{g}$ is the absorption coefficient of gas without soot, obtained from the WSGG model and $a_{s}$ is approximated as

$a_{s}=b_{1} \rho_{s}\left[1+b_{T}(T-2000)\right]$

with $b_{1}=1232.4 \mathrm{~m}^{2} / \mathrm{kg}, \rho_{s}$ denotes the soot density, and $b_{T}=4.8 \cdot 10^{-4} \mathrm{~K}^{-1}$.

\section{RESULTS AND DISCUSSION}

The present case study is a typical example where the CFD modeling can give much clearer insight into the processes in a furnace with design modifications. Practically all the parameters of the combustion process change when using the multi-staged (three-staged) combustion scheme. This fact, in turn, essentially influences the efficiency of the combustion process and the temperature field in the furnace.

Some results of the numerical simulations, comparing horizontal temperature profiles at different levels of the boiler furnce obtained by the use of DO and P-1 radiation models and measurements, as well, are presented in Figs. (3 and 4). The calculations were verified against the experimental data [28] and indicated good agreements in most cases, with some acceptable discrepancies. The temperature profiles showed that the use of over-fire air altered the nearburner temperatures, reducing the swirl relative to the incoming fuel. Similar effects are also properly predicted near the close-coupled over-fire air inlets. The general features of the flow indicate the formation of vortex that have reduced temperature levels at the middle of the furnace cross section in some cases, which is probably a result of the adverse pressure gradient.

Regarding the thermal radiation modelling approach, both models, the DO and the P-1, give relatively fair representationof the experimental results. In the most cases, the P1 model slightly overestimates the heat fluxes from localised heat sources. However, it must be pointed out that the calculation using the DO model is more time consuming. The ratio of the computing times using the models DO (with the S6 approximation, which means 48 flux directions) and the P1 is about 2.0. In the case of the DO with S4 approximation (24 flux directions), the ratio of the computing times is 1.75.

Additional information on the results of the numerical simulations, showing the influence of the two radiation models to other properties, such as the average furnace exit temperature, the total heat transfer rate to the furnace surfaces, char conversion at the furnace exit, etc., is given in Table 6.

An illustration of the change of the area-weighted average volume fractions of $\mathrm{O}_{2}$ and $\mathrm{CO}$ along the furnace height is given in Fig. (5).

Profiles of the change of the total surface heat flux along the furnace height, obtained with the two radiation models, together with the average surface heat fluxes, denoted as P1-m and DO-m, are presented in Fig. (6). 


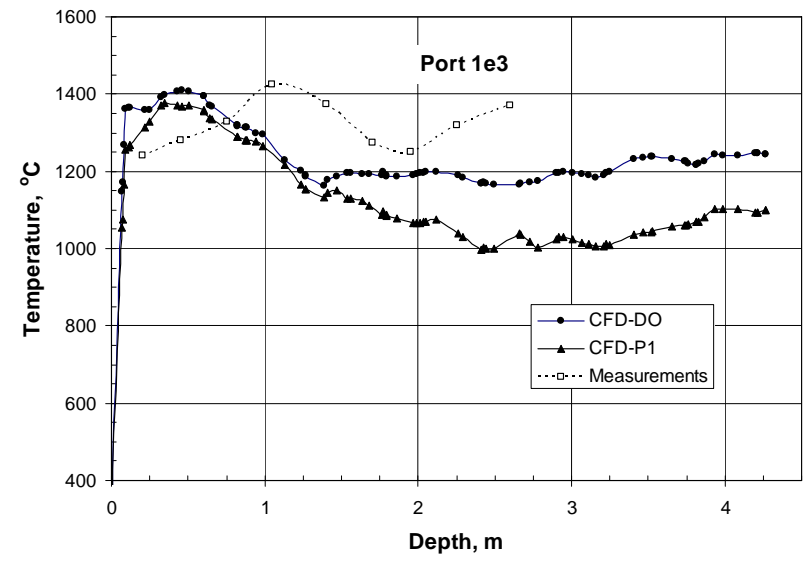

a)

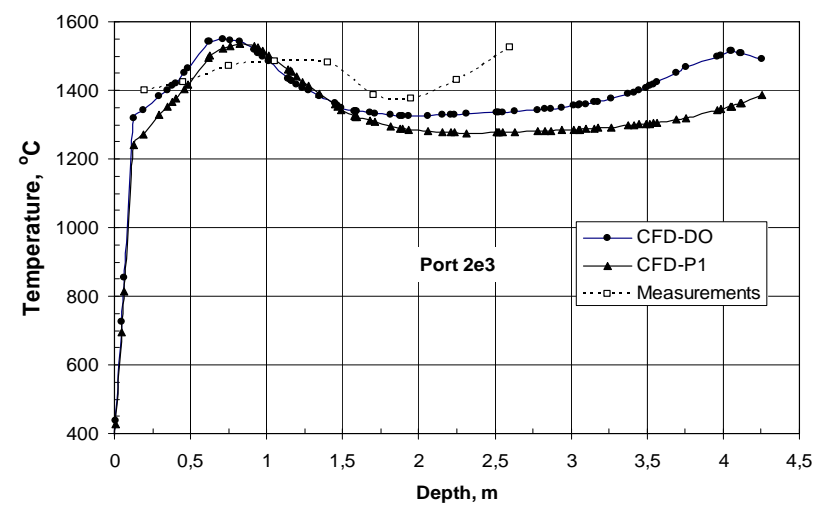

c)

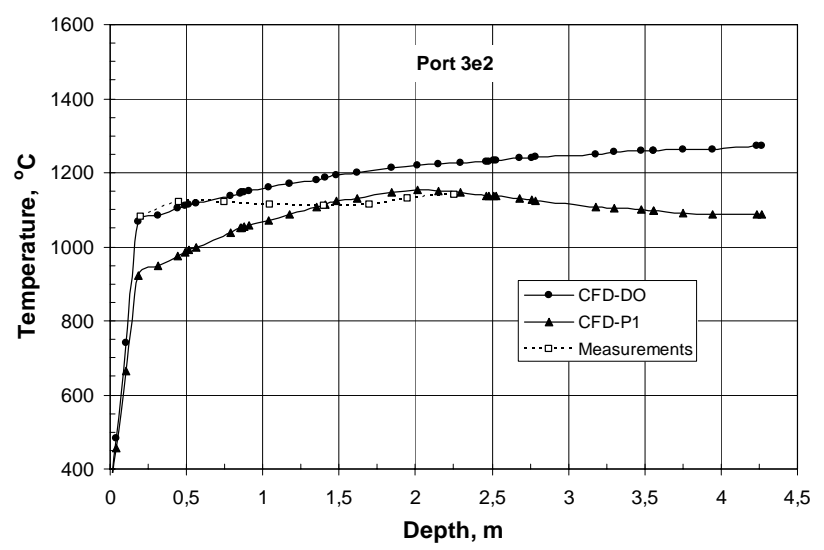

e)

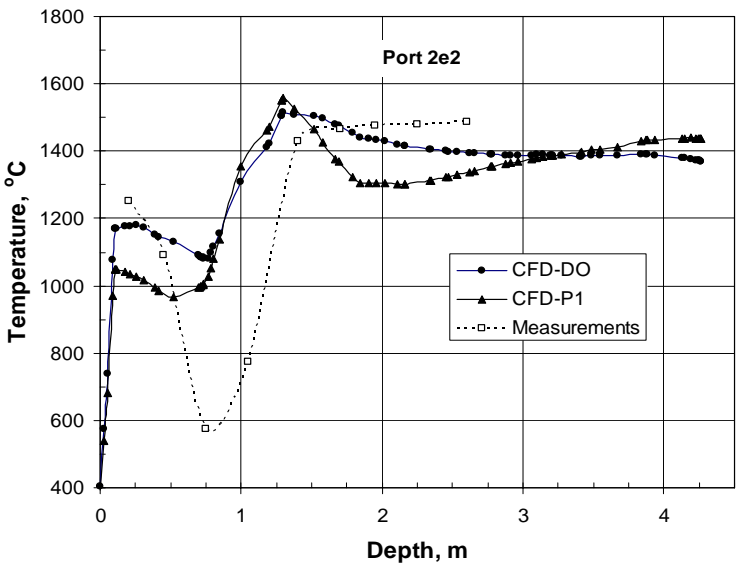

b)

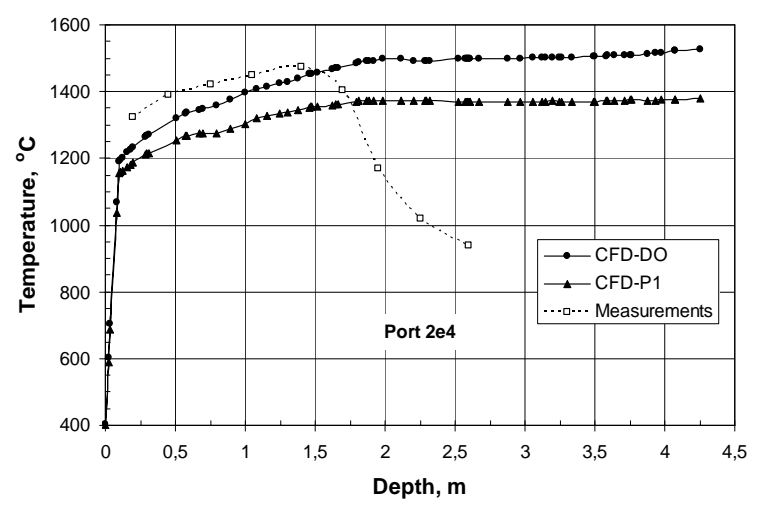

d)

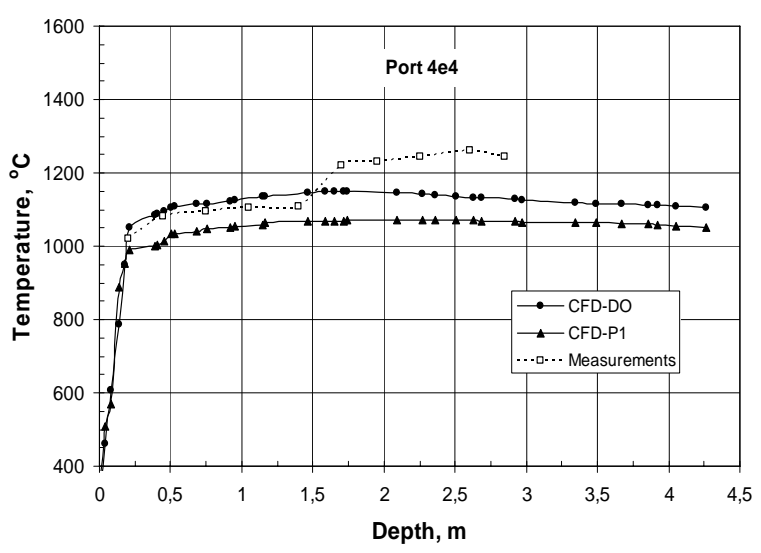

f)

Fig. (3). Temperature profiles on the east (right-hand) wall for three levels of SOFA: a) Port 1e3, b) Port 2e2, c) Port 2e3, d) Port 2e4, e) Port $3 \mathrm{e} 2$, f) Port $4 \mathrm{e} 4$.

From the comparison of predicted and measured temperatures, the relatively high fluctuations of calculated temperature profiles, as well as certain discrepancies between the numerical predictions and measurements are obvious. The largest differences appear in the burnout zone, near the fuel and air inlets, and they can be put down to several possible reasons. Such differences could indicate that the flow field in these areas may not be very well predicted. However, there were no possibilities to check the quality of the on a basis of the available experimental results. Another reason may be the tendency of the P-1 model to over-predict radiative fluxes from localised heat sources, as it is suggested in [40]. Also, an important, but still relatively under-researched modelling area - the particles-turbulence interaction, could be a reason for appearance of differences between the calculated and measured temperature profiles. Finally, it must be 


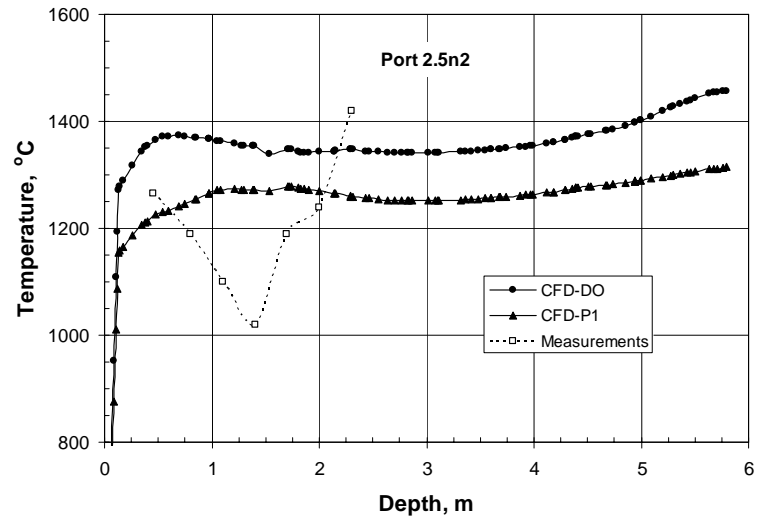

a)

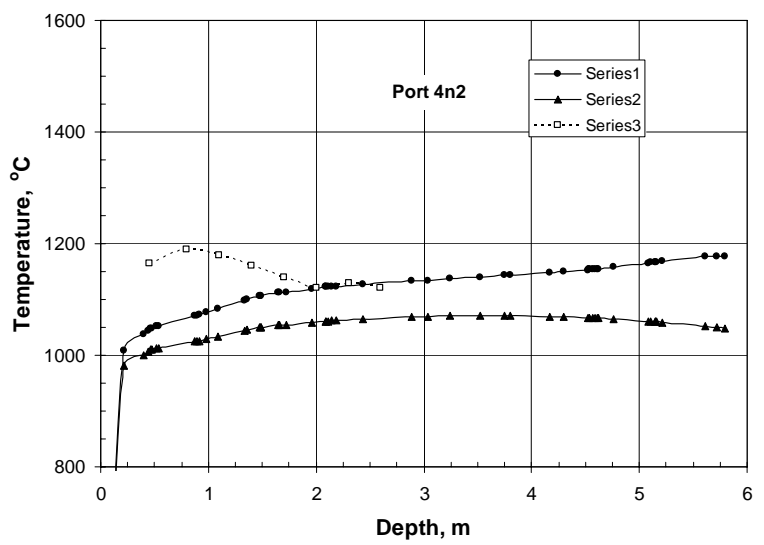

c)

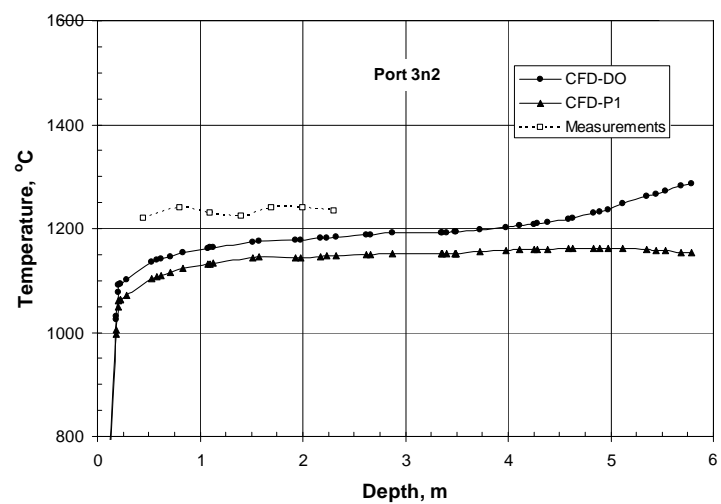

b)

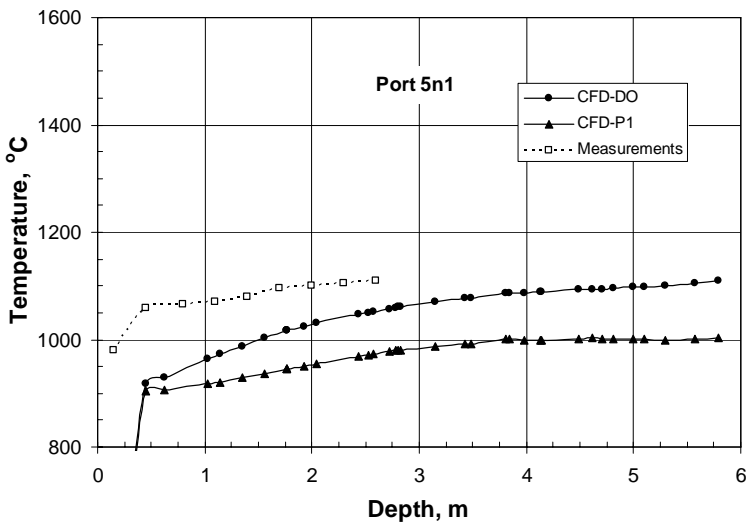

d)

Fig. (4). Temperature profiles on the north wall for three levels of SOFA: a) Port 2.5n2, b) Port 3n2, c) Port 4n2, d) Port 5n1.

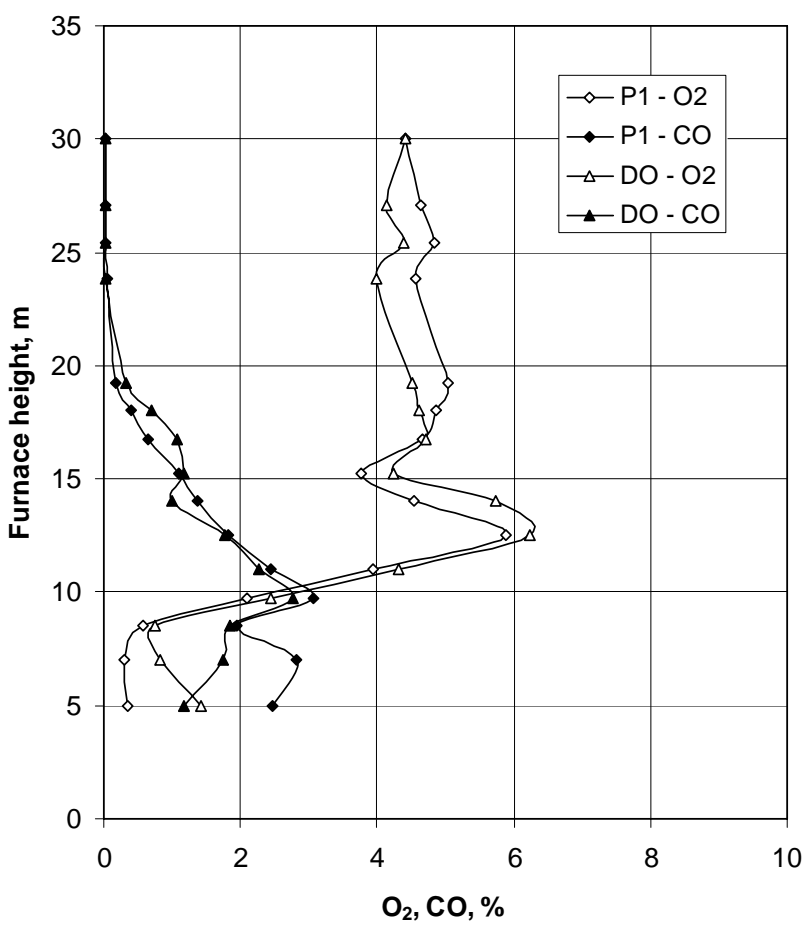

Fig. (5). Area-weighted average volume fractions of $\mathrm{O}_{2}$ and $\mathrm{CO}$ along the furnace height.
Table 6. Some Results of the Numerical Simulation

\begin{tabular}{|c|c|c|}
\hline \multirow{2}{*}{ Parameter, unit } & \multicolumn{2}{|c|}{ Value } \\
\cline { 2 - 3 } & P-1 model & DO model \\
\hline \hline $\begin{array}{c}\text { Furnace exit temperature (area-weighted } \\
\text { average), }{ }^{\circ} \mathrm{C}\end{array}$ & 922 & 945 \\
\hline $\begin{array}{c}\text { Total heat transfer rate to the furnace } \\
\text { surfaces, MW }\end{array}$ & 205.41 & 199.44 \\
\hline $\begin{array}{c}\text { Area-weighted average total surface heat } \\
\text { flux, } \mathrm{kW} / \mathrm{m}^{2}\end{array}$ & 151.9 & 147.5 \\
\hline $\begin{array}{c}\text { Char conversion, } \% \\
c\end{array}$ & 98.60 & 98.75 \\
\hline
\end{tabular}

pointed out that the variability of coal properties requires detailed characterisation data for validation purposes of the boiler furnace processes.

\section{CONCLUSIONS}

The main objective of the present study was to investigate how the results obtained with two radiative heat transfer methods, the P1 approximation method and the DO method, fit the temperature field in a boiler furnace on pulverised coal, with implemented OFA ports. Despite the evident discrepancies, in general, the both thermal radiation modelling approaches, with the DO and the P-1 models, give fair repre- 


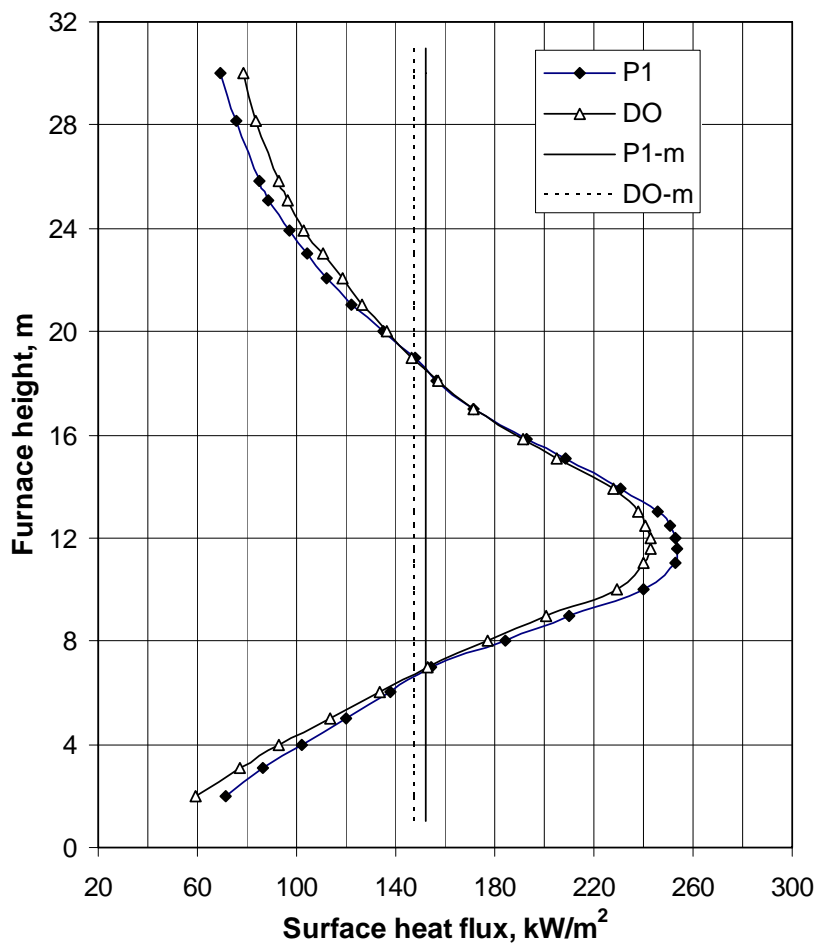

Fig. (6). Area-weighted average total surface heat flux along the furnace height.

sentation of the experimental results. The obtained temperature profiles with P-1 model are somewhat lower than in the case when the DO model is used. In that sense, the results obtained with the DO model better fit the measurements. The main differences between the modelling and the measurement values appear in the burnout zone, near the air/fuel injections, and need further investigation for appropriate explanation. In general, they can be addressed to several reasons: peculiarities of the flow field in the near-burner region, including the particles-turbulence interaction; the utilised thermal radiation models; and the variability of coal properties that requires much characterisation data for validation purposes of the boiler furnace processes. Finally, it must be noted that the computation with the DO model is more time consuming.

\section{REFERENCES}

[1] U. Schnell, "Numerical modelling of solid fuel combustion processes using advanced CFD-based simulation tools", Progress in Computational Fluid Dynamics, Vol. 1, No. 4, pp. 208-218, 2001.

[2] L. I. Diez, C. Cortes, A. Campo, "Modelling of pulverised coal boilers: review and validation of on-line simulation techniques", Applied Thermal Engineering, 25, pp. 1516-1533, 2005.

[3] N. V. Kuznetsov, V. V. Mitor, I. E. Dubovskiy, Ye. S. Karasina, M. M. Rubin, A. G. Blokh, Yu. L. Marshak, R. A Petrosyan, V. A. Lokshin, S. I. Mochan, P. N., Eds. Teplovoy raschet kotelynyih agregatov (Normativniy metod), Izd. Energiya, Moskva - Leningrad, 1973.

[4] Y. A. Zhuravlev, F. K. Sidorov, M. Y. Protsaylo, "Primenenie zonalynogo metoda dlya rascheta teploobmena v topke kotla", Teploenergetika, No 11, pp. 35-39, 1980.

[5] M. Y. Protsaylo, Y. A. Zhuravlev, "Issledovanie zonalynyim metodom vliyaniya rezhimnyih parametrov na teploobmen $\mathrm{v}$ topke kotla P-67”, Teploenergetika, No. 4, pp. 13-16, 1983.
H. C. Hottel, A. F. Sarofim, Radiative Transfer, McGraw-Hill, USA, 1967.

[7] G. Blokh. Heat Transfer in Steam Boiler Furnaces, London, Hemisphere Publishing, 1988.

[8] P. Ustimenko, K. B. Dzhakupov, V. O. Kroly, Chislennoe modelirovanie aerodinamimki i goreniya $v$ topochnyih i tehnologicheskih ustroystvah, Izd. "Nauka", Alma Ata, 1986.

[9] W. Fiveland, A. R. Wessel, "Numerical model for predicting performance of three-dimensional pulverized-fuel fired furnaces", Journal of Engeneering for Gas Turbines and Power, Vol. 110(11), pp. 117-126, 1988.

[10] J. Fan, L. Qian, Y. Ma, P. Sun, K. Cen, "Computational modelling of pulverized coal combustion processes in tangentially fired furnaces", Chemical Engineering Journal, Vol. 81(1), pp. 261-269, 2001.

[11] J. M. Jones, M. Pourkashanian, A. Williams, R. K. Chakraborty, J. Sykes, D. Laurence, "Modelling of coal combustion processes - a review of present status and future needs", In Proc. $15^{\text {th }}$ Annu. Intern. Pittsburgh Coal Conf. Pittsburgh, 1998; pp. 1-20.

[12] M. Eaton, L. D. Smoot, S. C. Hill, C. N. Eatough, "Components, formulations, solutions, evaluation, and application of comprehensive combustion models", Progress in Energy and Combustion Science, Vol. 25(4), pp.387-436, 1999.

[13] L. D. Smoot, "A decade of combustion research. Progress in Energy and Combustion Science, Vol. 23(3), pp.203-232, 1997.

[14] L. D. Smoot, "International Research Centers' Activities in Coal Combustion", Progress in Energy and Combustion Science, Vol. 24, pp.409-501, 1998.

[15] R. K. Boyd, J. H. Kent, "Three-dimensional furnace computer modelling", Proceedings of the $21^{\text {st }}$ Symposium (Int.) on Combustion, The Combustion Institute, Pittsburgh, 1986, pp. 265-274.

[16] S. C. Hill, L. D. Smoot, "A comprehensive three-dimensional model for simulation of combustion systems: PCGC-3", Energy \& Fuels, Vol. 7(6), pp.874-883, 1993.

[17] X. Y. Zhou, C. G. Zheng, Y. Y. Ma, "comparison of several discrete arithmetic schemes for simulating a constrained jet and a lab-scale tangential fired furnace", Computer Methods in Applied Mechanics and Engineering, Vol. 130(3-4), pp.279-288, 1996.

[18] A. Bermudez de Castro, J. L. Ferin, "Modelling and numerical solution of a pulverized coal furnace", Proceedings of the $4^{\text {th }}$ International Conference on Technologies and Combustion for Clean Environment, Lisbon, Portugal, paper 33.1, 1997, pp. 1-9.

[19] L. X. Zhou, L. Li, R. X. Li, J. Zhang, "Simulation of 3-d gas-particle flows and coal combustion in a tangentially fired furnace using a two-fluid-trajectory model", Powder Technology, Vol. 125(2), pp. 226-233, 2002.

[20] Yin, S. Caillat, J. L. Harion, B. Baudoin, E. Perez, "Investigation of the flow, combustion, heat-transfer and emissions from a $609 \mathrm{mw}$ utility tangentially fired pulverized coal boiler", Fuel, Vol. 81(8), pp.997-1006, 2002.

[21] W. A. Fiveland, "Three-dimensional radiative heat-transfer solutions by the discrete-ordinates method", Journal of Thermophysics, Vol. 2, No. 4, pp. 309-316, Oct. 1988.

[22] He, M. Chen, Q. Yu, S. Liu, L. Fan, S. Sun, J. Xu, W. P. Pan, "Numerical study of the optimum counter-flow mode of air jets in a large utility furnace", Computers \& Fluids, Vol. 33 (9), pp.12011223,2004

[23] J. Pallares, I. Arauzo, A. Williams, "Integration of CFD codes and advanced combustion models for quantitative burnout determination”, Fuel, Vol. 86, No. 15, pp. 2283-2290, Oct. 2007.

[24] H. Knaus, U. Schnell, K.R.G. Hein, "On the modelling of coal combustion in a $550 \mathrm{MWel}$ coal-fired utility boiler", Progress in Computational Fluid Dynamics, Vol. 1, No. 4, pp. 194-207, 2001.

[25] C. Ratzel III, J. R. Howell, "Two-dimensional radiation in absorbing-emitting media using the p-n approximation", Journal of Heat Transfer, Transactions of the ASME, Vol. 105, pp.333-340, 1983.

[26] R. V. Filkoski, I. J. Petrovski, P. Karas, "Optimisation of pulverised coal combustion by means of CFD/CTA modelling", Thermal Science (An International Journal), Vol. 10, No. 3, pp.161-179, 2006.

[27] R. V. Filkoski, S. V. Belosevic,, I. J. Petrovski, S. N. Oka, M. A. Sijercic, "Cfd technique as a tool for description of the phenomena occurring in pulverised coal combustion systems", Proc. IMechE, Journal of Power and Energy, Vol. 221 Part A: pp.399-409, 2007. 
[28] R. Tree, B. W. Webb, "Local temperature measurements in a full-scale utility boiler with overfire air", Fuel, Vol. 76, No. 11, pp. 1057-1066, 1997.

[29] R. V. Filkoski, "Modelling of thermal processes and optimisation of energetic-environmental characteristics of modern boiler plants", Ph.D. thesis, University "Ss Cyril and Methodius", Skopje, 2004.

[30] C. Wilcox, Turbulence Modelling for CFD, second ed., DWC Industries, La Canada, California, 1998.

[31] K. Kuo, Principles of Combustion, John Wiley \& Sons, New York - Chichester - Brisbane - Toronto - Singapore, 1986.

[32] E. Khalil, Modelling of Furnaces and Combustors, Abacus Press, Tunbridge Wells, Kent, 1982.

[33] R. Siegel, J. R. Howel, Thermal Radiation Heat Transfer, Hemisphere Publ. Corp., Washington D.C., 1992.

[34] Zh. Guo, S. Kumar, "Three-dimensional discrete ordinates method in transient radiative transfer", Journal of Thermophysics and Heat Transfer, Vol. 16, No. 3, pp. 289-296, July-September 2002.
[35] Dorri-Nowkoorani, R. I. Dougherty, "Modified $\mathrm{p}_{\mathrm{n}}$ for correlation transfer in one-dimensional scattering and absorbing media", Journal of Thermophysics and Heat Transfer, Vol. 16, No. 4, pp. 529-536, Oct.-Dec. 2002.

[36] N. G. Shah, "A new method of computation of radiant heat transfer in combustion chambers", Ph.D. Thesis, Imperial College of Science and Technology, London, 1979

[37] G. Blokh, Y. A. Kuravlev, L. N. Ryzhkov, Teploobmen izlucheniem, Energoatomizdat, Moskva, 1991

[38] J. Rusas, "Numerical simulation of gas-particle flow linked to pulverized coal combustion", Ph.D. Thesis, Inst. of Energy Technology, Aalborg University, Aalborg, Denmark, 1998

[39] M. F. Modest, "The weighted-sum-of-gray-gases model for arbitrary solution methods in radiative transfer", Journal of Heat Transfer, Vol. 113, No. 3, pp. 650-656, August 1991.

[40] Fluent 6.1 User's Guide, Fluent Inc., Lebanon NH, USA, 2003.

Received: August 31, 2009

Revised: October 13, 2009

Accepted: October 13, 2009

(C) Risto V. Filkoski; Licensee Bentham Open.

This is an open access article licensed under the terms of the Creative Commons Attribution Non-Commercial License

(http://creativecommons.org/licenses/by-nc/3.0/) which permits unrestricted, non-commercial use, distribution and reproduction in any medium, provided the work is properly cited. 